\title{
Pseudagrion lalakense spec. nov. from Borneo with notes on its ecology (Odonata: Coenagrionidae)
}

\author{
Albert G. Orr' \& Jan van Tol ${ }^{2}$ \\ 'Author for correspondence. Cooperative Research Centre for Tropical Rainforest \\ Ecology and Management, Environmental Sciences, Griffith University, \\ Nathan, Q 4111, Australia. <agorr@universal.net.au> \\ ${ }^{2}$ National Museum of Natural History Naturalis, P.O. Box 9517, \\ NL-2300 RA Leiden, The Netherlands. <tol@nnm.nl>
}

Received 12 October 2000; revised and accepted 20 January 2001.

Key words: Odonata, dragonfly, Zygoptera, Coenagrionidae, Borneo, Pseudagrion, ecology, behaviour.

\begin{abstract}
Pseudagrion lalakense, a new species of coenagrionid from Borneo, is described and figured. The species is phylogenetically close to the very widespread and eurytopic $P$. microcephalum and the two fly together. $P$. lalakense may be distinguished from microcephalum and several other similar blue species by the pattern on the thorax and abdomen in both sexes and by the form of the male terminal appendages. $P$. lalakense is highly stenotopic, being known only from highly acidic black-water marsh in two localities in Brunei where it is associated with the sedge Hydrolitha. Activity patterns of $P$. lalakense appear similar to those of $P$. microcephalum but the two species differ in their preferred perches and oviposition sites. A list of seven species of other odonates flying in the same habitat is provided.
\end{abstract}

\section{Introduction}

The genus Pseudagrion is widely distributed in the old world tropics and subtropics. $P$. microcephalum (Rambur) is found from India to Northern Australia (Fraser 1933; Lieftinck 1932, 1936, 1937, 1949, 1954; Lieftinck et al. 1984; Watson et al. 1991). It occurs sympatrically with several closely related vicariant species of more limited distribution, several of which were first illustrated by Ris (1916) as forms of microcephalum, but have since been shown to be distinct species, largely on the basis of the structure of the male superior appendages (Lieftinck 1937). At present three species of the genus are known from Borneo, including $P$. microcephalum, $P$. coomansi Lieftinck and the more distantly related $P$. perfuscatum Lieftinck. Recently, one of us (A.G. Orr) discovered a highly localized population of a new form, flying together with $P$. microcephalum in a black-water marsh in Brunei. Although obviously close to microcephalum it differs substantially and consistently from it and related species in the thoracic and abdominal markings in both 
sexes and in the shape of the male appendages. On the basis of a substantial series, collected on widely different dates over a period of two and a half years, and numerous behavioral observations, we feel justified in describing this form as a new species. The following abbreviations are used in the text: RMNH, National Museum of Natural History Naturalis, Leiden; UBD, Universiti Brunei Darussalam. Time of day is given by local time; the sun was directly overhead at 12:00 $\pm 00: 05 \mathrm{~h}$ during periods of observation.

\section{Pseudagrion lalakense spec. nov.}

\section{Type material}

(Fig. 1 a-f)

Holotype $\delta$, Brunei, Belait District, Luagan Lalak in main channel. (04\%31'10"N, 114²8'22”E), 17 iv 1994, leg. A.G. Orr, (in RMNH). Paratypes, 20 $0^{\star}, 4$ ㅇ (all Luagan Lalak, Brunei, leg. A.G. Orr): 2ठ, 29 i 1993; $1 \delta^{\star}, 1$ xi 1993; $2 \delta^{\star} 17$ iv 1994; $3 \delta^{\star}, 24$ iv 1994; $1 \delta, 1 \times 1995 ; 1 \delta^{\star}, 1$ \% (in cop.), 6 x1995 (all in RMNH); 4ठ, 1 \% , 6 x 1995 (Cambridge University, Zoology Dept. Museum); $1 \delta$, 1 (in cop.), 6 x 1995 (UBD Biology Dept. Museum); 5ð், 1 \%, 6 x 1995 (A.G. Orr collection).

\section{Description}

\section{Male holotype}

Head: Anterior part, including labrum, outer face of mandibles, genae, frons and clypeus bright azure blue, broken only by a small median black spot at base of labrum, by three spots along the fronto-clypeal margin and by a small median spot in the transverse frontal fissure. The blue area reaches the vertex, level with the anterior ocellus, with two fine blue lines extending back to the lateral ocelli sometimes contiguous with a small blue mark between the lateral ocelli. Remainder of vertex black. Occiput black with narrow blue band along its posterior margin. Posterior half of postocular lobe nearly filled with a conspicuous blue suboval spot. Antennae with first segment blue, the remainder black. Ventrally, labium and maxillae creamy white.

Thorax: Prothorax with anterior, posterior and lateral lobes blue. Dorsum black with median rectangular blue spot, divided by a fine longitudinal black line, and elongated blue marks on either side. Synthorax azure blue and black (Fig. 1a). Mesepisternum with median dorsal black band flanked by broad antehumeral blue bands. Humeral black bands are also broad, contiguous with a black band bisecting the mesinfraepisternum cephalad, and with sinuous margins caudad resulting in a subterminal expansion narrowing to a point at its junction with the antealar ridge. Remainder of synthorax blue with the exception of a small black spot on the interpleural suture about one third of its length from the subalar ridge, and a posteriorly flat-sided crescent shaped mark at the dorsal end of the metapleural suture. Legs black posteriorly, pale cream anteriorly. Wings transparent and colourless with veins black; forewings with 10-11 Px; hindwings with 9 Px; pterostigma diamond shaped, dark brown.

Abdomen: ground colour blue with bronzy black dorsal marking as follows (Fig. 1b): Segment (S) 1 with basal black patch reaching as far as the midpoint of the segment. S2 with angular black mark, placed slightly caudad, with two short anterior arms; 

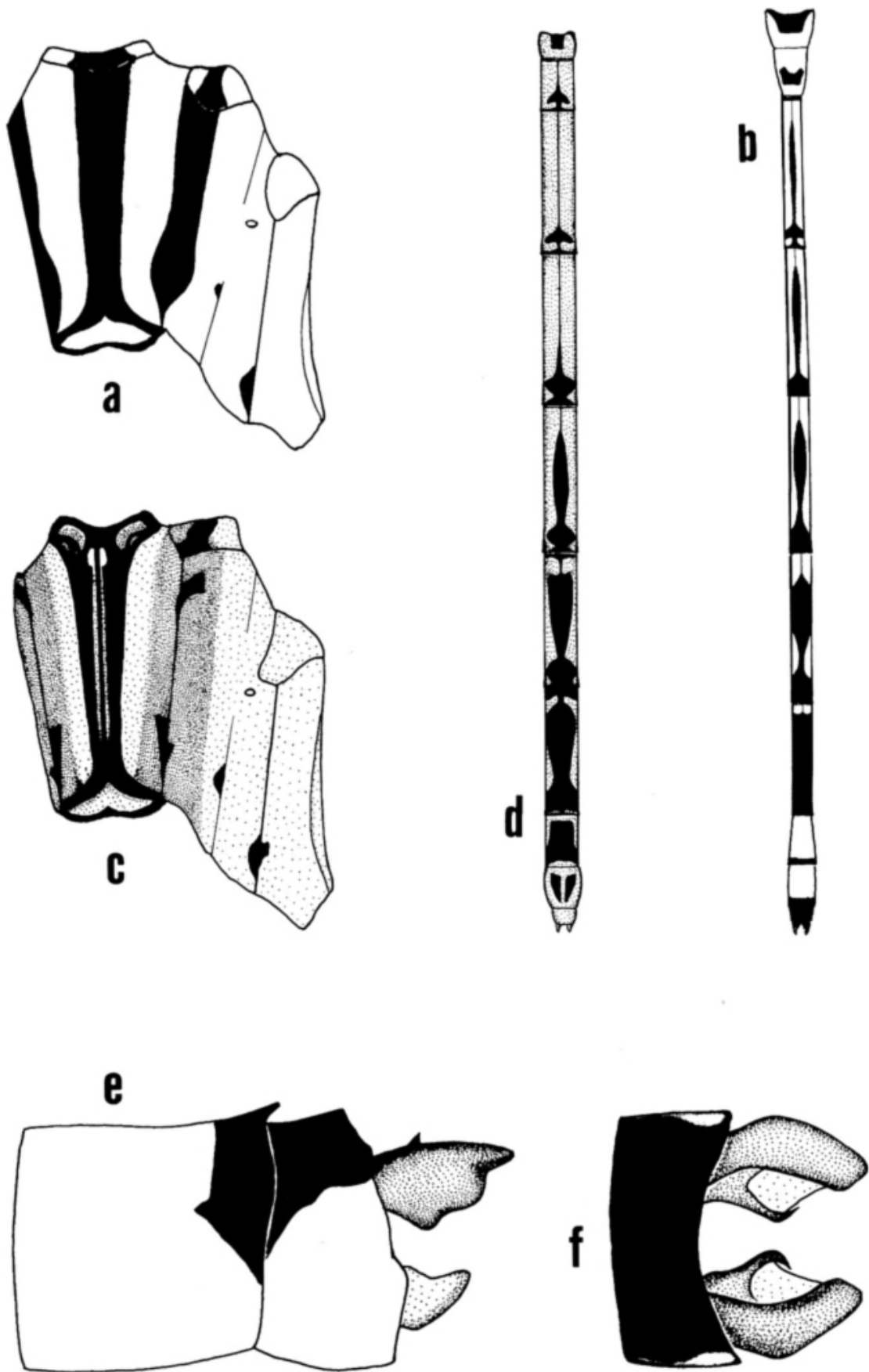

Figure 1. Pseudagrion lalakense spec. nov. - (a) dorsolateral view of male synthorax; (b) dorsal view of male abdomen; (c) dorsolateral view of female synthorax; (d) dorsal view of female abdomen; (e) lateral view of male segment 9, 10 and anal appendages; (f) dorsal view of male segment 10 and superior appendages. 
not approaching anterior or posterior margins of the segment. S3-6 with a series of median dorsal lanceolate markings, (successively thicker from S4-6) broad posteriorly and narrowing to a point anteriorly, thence connected to the anterior margin of the segment by an extremely fine, scarcely visible, line. S3 with thin band around anterior margin and broad saddle-like expansion of dorsal marking posteriorly, delimiting two subterminal lateral blue spots. S7 extensively black, with thin blue band around anterior margin. S8-9 blue with black band around posterior margin. S10 black, sides blue. S10 short (ca 3 times as broad as long mid-dorsally) (Fig. 1 e, f). Superior appendage black, of medium length (ca 1.7 times as long as $\mathrm{S10}$ ) and broad, with a blunt ventral prominence and shallow distal notch. Broad interior expansion with a long, dorsally directed, slightly curved spine, the tip of which is just visible externally in lateral view. Inferior appendage cream (pale blue in well preserved specimens), short, roughly triangular in profile and rounded terminally.

Measurements (mm): Hindwing 17.2, abdomen including appendages 28.1 .

\section{Female (paratype)}

Ground colour pale greenish blue and greenish bronze with black markings. Bronze areas largely replace black of the male on thorax.

Head: Markings similar to male but blue is mostly replaced by blueish green except for post occipital spots which are blue as in the male, but larger.

Thorax: Prothoracic markings similar to those of male but pale areas greenish-blue and more extensive. Posterior lobe with two very thin, well separated pale coloured prongs arising from its margin, reaching forward to about the middle of median lobe. Synthorax: (Fig. 1c) Mesepisternum with median dorsal black band enclosing near its anterior margin two crescent shaped lateral bronze marks, and two small green spots on either side of the dorsal carina connected to two thin parallel bronze lines flanking the carina, and extending four-fifths of the way to the antealar ridge. Remainder of synthorax pale greenish blue except for a poorly delimited broad bronze band around the mesopleural suture which extends into the anterior part of the mesinfraepisternum, small black markings at distal and anterior ends of mesopleural suture, and black markings corresponding to those of the male on the mesokatepisternum, and intersegmental and mesopleural sutures. Legs and wings similar to male. Forewing Px 10; hindwing Px 8.

Abdomen (Fig. 1d): Greenish blue with dorsal black markings becoming progressively broader in posterior segments. S1 as in male. S2 with broad triangular mark, its vertex directed cephalad, bisected by thin line reaching anterior and posterior margins. S3-4 with thin median line expanded posteriorly into a narrow saddle-like marking delimiting two pale lateral submarginal spots. S5-8 with dorsal lanceolate markings as in male, becoming broader and less well defined anteriorly in S7 and S8. S9 with two triangular marks; S10 pale and unmarked. Anal appendages conical, shorter than S10, dark basally and pale distally.

Measurements (mm): Hindwing 17.1, abdomen plus appendages 25.7.

\section{Variation}

Males vary principally in the ratio of black to blue coloration. This is most apparent on the abdomen where the black mark on the dorsum of $\mathrm{S} 2$ varies in size by a factor 
of about 1.5. The dark lanceolate dorsal mark may be reduced to a thin streak in S3, and be considerably narrower in S4 and S5 than in the specimen figured (Fig. 1b). Some specimens have extensive blue marking on the dorsum of S10. Females vary in the width of the median black band on the mesepisternum and the extent of the parallel bronze lines flanking the dorsal carina, which are sometimes contiguous with the pale antehumeral areas, and in the extent of dorsal black marking on the abdomen. In some specimens S9 is almost entirely black, and in others mostly pale.

There is little variation in size $(\mathrm{mm})$ - males: $\mathrm{hw}$ 15.5-18.1, $\mathrm{x}=17.2 \mathrm{sd}=0.6$, $n=21$; females: $17.1-18.7, \mathrm{x}=17.7$, sd $=0.7, n=4$; or venational characters - males $\mathrm{Px}$ hw 9 rarely 10, Px fw 10-11; females Px hw 8, rarely 9, Px fw 10.

\section{Differential diagnosis}

Males differ from all described species, including microcephalum, in the form of the superior appendages, in the shape and isolation of the black mark on S2, and in the reduction of the black dorsal marking on S3-5. There are distinct differences in pattern between microcephalum and lalakense, pale specimens of the former showing greater development of blue on the vertex and prothorax, whereas those of the latter show greater development of blue on the abdomen, particularly the anterior segments. The greater extent of blue in the anterior abdominal segments of lalakense enables it to be recognized reliably in flight. Females differ from those of microcephalum in the markings of the synthorax, in particular the broad median black area on the mesepisternum which is represented by only a thin line in microcephalum, in the complex markings enclosed within this area, in the black marks along the mesopleural suture (much smaller or lacking in microcephalum), and in the narrow dorsal black markings on $\mathrm{S} 3-5$, as in the male.

\section{Etymology}

Named after the type locality, on account of its apparently extremely restricted range; lalak is a Malay word signifying the touch-hole of a cannon, the name of the lagoon or marsh (= luagan) probably being derived from the relation it bears to the main river.

\section{Habitat and behaviour}

Pseudagrion lalakense is now known only from Luagan Lalak, Belait District, Brunei. This is a highly acidic $(\mathrm{pH}=3.9)$ blackwater marsh approximately 28 ha in area draining into the Belait River. A second habitat nearby at Sg Badas has been destroyed by development. The marsh floods periodically but at the times of observations there was, running through its centre, an open channel 1-7 $\mathrm{m}$ wide and 2-3 $\mathrm{m}$ deep, in which a slight but perceptible current flowed. The channel was fringed with narrow belt of a coarse leafed sedge of the genus Hydrolitha. Waterlilies (Nymphaea sp.) grow along the edge in small clumps consisting of only a few leaves every $10-20 \mathrm{~m}$ and more rarely in the center of the channel. Males of $P$. lalakense rested chiefly on Hydrolitha leaves 
at the edge of the channel, and were never seen more than $15 \mathrm{~m}$ from the channel beyond the Hydrolitha zone. In the morning, between 09:00 h and 12:00 h males spaced themselves along the margins of the channel and were relatively sedentary. Mating was once observed before 11:00 $\mathrm{h}$ but maximal sexual activity occurred between $13: 30 \mathrm{~h}$ and 14:30 $\mathrm{h}$, when numerous mating pairs could be seen, frequently being chased by other males. Oviposition was in tandem and females inserted their eggs in the undersides of water lily leaves. The pattern of activity was similar to that of P. microcephalum, which occurred in the same locality, but differed in its habits in that the males perched either on lily pads or on vegetation other than Hydrolitha. Females of $P$. microcephalum tended to oviposit on lily pads located more centrally in the channel. $P$. microcephalum was distributed generally over the entire marsh but was less common than $P$. lalakense in the main channel. The fauna of the lake is rather depauperate and most other odonates found in the area are unexceptional, apart from one other species, the small libellulid Chalybaeothemis fluvialis Lieftinck, which is also restricted to habitats of this type. Other species found include the coenagrionid Ceriagrion cerinorubellum (Brauer), the libellulids Rhyothemis aterrima Selys, R. obsolescens Kirby, Urothemis signata (Rambur), Brachydiplax chalybea Brauer and the corduliid Epophthalmia vittigera (Rambur) all species which are widely distributed in areas of standing water throughout Borneo.

\section{Acknowledgements}

We would like to express our gratitude to Drs Jonathan Davies, Indraneil Das and Joseph Charles for assistance in the field.

\section{References}

Fraser, F.C., 1933. The fauna of British India including Ceylon and Burma: Odonata Volume I. Taylor and Francis, London.

Lieftinck, M.A., 1932. The dragonflies (Odonata) of New Guinea and neighbouring islands. Part 1. Descriptions of new genera and species of the families Lestidae and Agrionidae. Nova Guinea 15: 485-602.

Lieftinck, M.A., 1936. Die Odonaten der Kleinen Sunda-Inseln. Revue Suisse Zoologie 43: 99-160.

Lieftinck, M.A., 1937. Descriptions and records of South-east Asiatic Odonata. Treubia 16: 55-119.

Lieftinck, M.A., 1949. Synopsis of the Odonate fauna of the Bismarck Archipelago and the Solomon islands. Treubia 20: 319-374.

Lieftinck, M.A., 1954. Handlist of Malaysian Odonata. A catalogue of the dragonflies of the Malay peninsula, Sumatra, Java and Borneo, including the adjacent small islands. Treubia (Suppl.) 22: 1-202.

Lieftinck, M.A., J.C. Lien \& T.C. Maa, 1984. Catalogue of Taiwanese dragonflies (Insecta: Odonata). Asian Ecological Society, Taichung, Taiwan.

Ris, F., 1916, H. Sauter's Formosa-Ausbeute. Odonata. (Mit Notizen über andere ostasiatische Odonaten.). Supplementa Entomologica 5: 1-81.

Watson, J.A.L., G. Theischinger \& H.M. Abbey, 1991. The Australian dragonflies. CSIRO, Melbourne. 